\title{
Geotail observations of two-component protons in the midnight plasma sheet
}

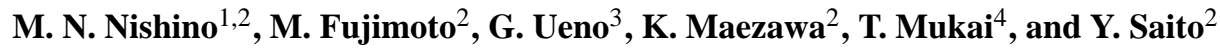 \\ ${ }^{1}$ School of Science, The University of Tokyo, Tokyo 113-0033, Japan \\ ${ }^{2}$ ISAS/JAXA, Kanagawa 229-8510, Japan \\ ${ }^{3}$ Institute of Statistical Mathematics, Tokyo 106-8569, Japan \\ ${ }^{4}$ JAXA, Tokyo 100-8260, Japan
}

Received: 5 March 2007 - Revised: 3 September 2007 - Accepted: 18 October 2007 - Published: 6 November 2007

\begin{abstract}
Through the effort to obtain clues toward understanding of transport of cold plasma in the nearEarth magnetotail under northward IMF, we find that twocomponent protons are observed in the midnight plasma sheet $\left(-10>X_{\mathrm{GSM}}>-30 R_{E},\left|Y_{\mathrm{GSM}}\right|<10 R_{E}\right)$ under northward IMF by the Geotail spacecraft. Since the twocomponent protons are frequently observed on the duskside during northward IMF intervals but hardly on the dawnside, those found in the midnight plasma sheet are thought to come from the dusk flank. The cold proton component in the midnight region occasionally has a parallel anisotropy, which resembles that in the tail flank on the duskside. The flows in the plasma sheet with two-component protons were quite stagnant or slightly going dawnward, which supports the idea that the observed two-component protons in the midnight region are of duskside origin. Because the two-component protons in the midnight plasma sheet emerge under strongly northward IMF with the latitudinal angle larger than 45 degrees, and because the lag from the strongly northward IMF to the emergence can be as short as a few hours, we suggest that prompt plasma transport from the dusk to midnight region occurs under strongly northward IMF. We propose that the dawnward flows result from viscous interaction between the high-latitude portion of the plasma sheet and the lobe cell. Another candidate for plasma transport process from the dusk to the midnight region is turbulent flow due to vortical structures of the Kelvin-Helmholtz instability that developed around the dusk low-latitude boundary under strongly northward IMF. In addition, we also suggest that gradual cooling of hot protons under northward IMF is a global phenomenon in the near-Earth magnetotail.
\end{abstract}

Keywords. Magnetospheric physics (Magnetotail; Plasma convection; Plasma sheet)

Correspondence to: $\mathrm{M}$. N. Nishino

(nishino@stp.isas.jaxa.jp)

\section{Introduction}

It is important to know signatures of the plasma sheet in the Earth's magnetosphere, because the plasma sheet works as a plasma reservoir and plays important roles in magnetospheric dynamics. It has been known that the plasma sheet in the near-Earth magnetosphere becomes cold and dense under northward IMF (e.g. Zwolakowska et al., 1992; Zwolakowska and Popielawska, 1992; Terasawa et al., 1997; Borovsky et al., 1998; Nishino et al., 2002; Wing et al., 2005). The cold plasma is thought to be of solar wind origin and to come into the magnetosphere across the lowlatitude boundary, because it is often found in both flanks (Terasawa et al., 1997). Continuous spatial distribution of the cold plasma from the dusk flank to deeper inside the plasma sheet also supports the idea that solar wind plasma intrudes into the plasma sheet (Fujimoto et al., 1998). While the cold plasma is frequently found in both flanks, we notice that the cold plasma is occasionally found in the midnight region as well. Zwolakowska et al. (1992) reported that the cold plasma is observed in the high-latitude portion of the midnight plasma sheet under northward IMF. Nishino et al. (2002) also pointed out that the cold plasma sheet emerges in the midnight region under northward IMF. A recent observational study showed that the plasma sheet in the midnight region becomes cold under strongly northward IMF, basing on the data remote-sensed from low altitude satellites (Øieroset et al., 2005). These studies implied that the cold plasma may come into the flank regions and then moves toward the midnight region under northward IMF. Solar wind entry across the magnetopause as well as cold plasma transport in the magnetotail is under debate at present.

Inspection of the proton distribution function may be useful for obtaining information on the origin of the cold plasma found in the midnight region, because one of the features of the cold plasma sheet should be a dawn-dusk asymmetry found in the velocity distribution function of protons. It has

Published by Copernicus Publications on behalf of the European Geosciences Union. 
been known that protons on the duskside occasionally consist of two separate (cold and hot) components under northward IMF while those on the dawnside usually do of one component that is dominated by low-energy (cold) ions (Hasegawa et al., 2003; Wing et al., 2005). The two components on the duskside are thought to have different origins; the cold component is thought to come from solar wind, and the hot one is of magnetosphere origin. The cold proton component in the plasma sheet near the dusk low-latitude boundary occasionally has a temperature anisotropy (Traver et al., 1991), and the sense of the anisotropy depends on the locations; it has a parallel anisotropy in the tail flank and a perpendicular anisotropy on the dayside (Nishino et al., 2007).

In addition to the proton velocity distribution functions, time lag of response of the midnight plasma sheet to the northward IMF may bring us some information on plasma transport in the near-Earth plasma sheet as well as on plasma entry under northward IMF. Terasawa et al. (1997) proposed a diffusive transport from the solar wind into the plasma sheet under northward IMF, showing a time scale as long as $9 \mathrm{~h}$. Wing et al. $(2005,2006)$ suggested the cold plasma sheet formation in the flanks by a lag of about $3 \mathrm{~h}$, and discussed that the cold plasma sheet formation can be explained either by diffusive processes or high-latitude reconnection.

In this paper, we present that two-component protons are found in the midnight plasma sheet under strongly northward IMF, suggesting prompt plasma transport from dusk to midnight region in the near-Earth magnetotail.

\section{Instrumentation}

We use moment data obtained every $12 \mathrm{~s}$ by the low energy particle (Geotail/LEP) experiment (Mukai et al., 1994) and the magnetic field data obtained by the flux-gate magnetometer (Geotail/MGF) (Kokubun et al., 1994). The ion energy-per-charge analyzer of LEP-EAi detects ions between $32 \mathrm{eV} / \mathrm{q}$ and $39 \mathrm{keV} / \mathrm{q}$, which covers most of typical energy range of plasma sheet ions. All of detected positivelycharged ions are assumed to be protons. The moment calculations are performed onboard Geotail (see Mukai et al., 1994, for details). We also use data from 3-D ion distribution functions obtained by Geotail/LEP, although the data exist for limited intervals. From the 3-D distribution functions, we obtain plasma moment parameters of the cold and hot proton components separately, using a two-Maxwellian mixture model with a scheme developed by Ueno et al. (2001). Perpendicular and parallel temperatures of the cold (hot) proton component are denoted as $T_{\mathrm{C} \perp}$ and $T_{\mathrm{C} \|}\left(T_{\mathrm{H} \perp}\right.$ and $\left.T_{\mathrm{H} \|}\right)$, respectively. The estimation error of the ion bulk velocity is considered to be less than a few percent of the thermal velocity; for example, an error bar for ions whose temperature is $200 \mathrm{eV}$ is within several $\mathrm{km} / \mathrm{s}$.
Solar wind parameters observed by the Wind and ACE spacecraft are provided by the CDAWeb. We use the GSM coordinate system throughout the paper.

\section{Case studies}

\subsection{May 2001 event}

We perform a case study of two-component protons in the midnight plasma sheet on 16 May 2001. Figure 1 shows the Geotail data between 12:00-20:00 UT. From the top, (a) energy-time (E-t) spectrogram of protons (omni-directional summation of 2-D data) in keV/q, (b) proton temperature in $\mathrm{eV}$, (c) proton density in $\mathrm{cm}^{-3}$, (d) $V_{\mathrm{X}}$ (black line) and $V_{\perp \mathrm{X}}$ (red line: velocity perpendicular to the local magnetic field) in $\mathrm{km} / \mathrm{s}$, (e) $V_{Y}$ and $V_{\perp \mathrm{Y}}$ in $\mathrm{km} / \mathrm{s}$, and (f) three components of the magnetic field in $\mathrm{nT}$ are presented. The spacecraft locations in the GSM coordinate are shown at the bottom of the figure. Before 15:00 UT, Geotail stayed in the hot and tenuous plasma sheet whose temperature gradually decreased from $7 \mathrm{keV}$ to $4 \mathrm{keV}$ between 12:00-14:50 UT. Between 14:50-15:03 UT the low-energy proton flux $(\sim 1 \mathrm{keV})$ gradually increased and the temperature of protons decreased to be $2.6 \mathrm{keV}$. Geotail encountered the two-component protons around 15:03 UT as it relatively moved to high-latitude portion of the northern plasma sheet where the magnetic field was $(7.0,0.6,0.7) \mathrm{nT}$. The location of Geotail around 15:03 UT was $(-20.9,3.5,4.6) R_{E}$. The temperature and density of the two-component protons obtained from onboard moment calculation were about $1.5-1.8 \mathrm{keV}$ and $0.5-0.8 \mathrm{~cm}^{-3}$, respectively. The observation of the twocomponent protons ended around 19:00 UT when Geotail was $(-19.3,-0.6,3.7) R_{E}$, as the border between the two components became ambiguous.

The two-component protons were superposition of the cold component with a peak (in count) around $1 \mathrm{keV}$ and the hot component with a peak around several $\sim 10 \mathrm{keV}$, which resemble those observed on the duskside (Nishino et al., 2007). A dawnward-tailward flow ( $\left.V_{\mathrm{X}}, V_{\mathrm{Y}} \sim-50 \mathrm{~km} / \mathrm{s}\right)$ was observed when the cold component emerged (15:0215:17 UT). After the emergence of the two-component protons, dawnward-tailward flows were frequently observed (e.g. 15:27-15:51 UT). The average flow direction between 15:03-17:05 UT was $(-10,-14,7) \mathrm{km} / \mathrm{s}$, which is opposite to the average flow pattern in the near-Earth plasma sheet (Hori et al., 2000). Note that $V_{\mathrm{Y}}$ was almost same as $V_{\perp \mathrm{Y}}$, which means that the observed dawnward flows were cross field plasma transport. Before the emergence of the twocomponent protons and after 17:05 UT, the flow directions were consistent with the average pattern; that is, duskward flows were observed. Since the spacecraft was predominantly in the Northern Hemisphere before 17:05 UT while it stayed in the Southern Hemisphere after that, the flow directions might depend on the hemisphere. The duskward 


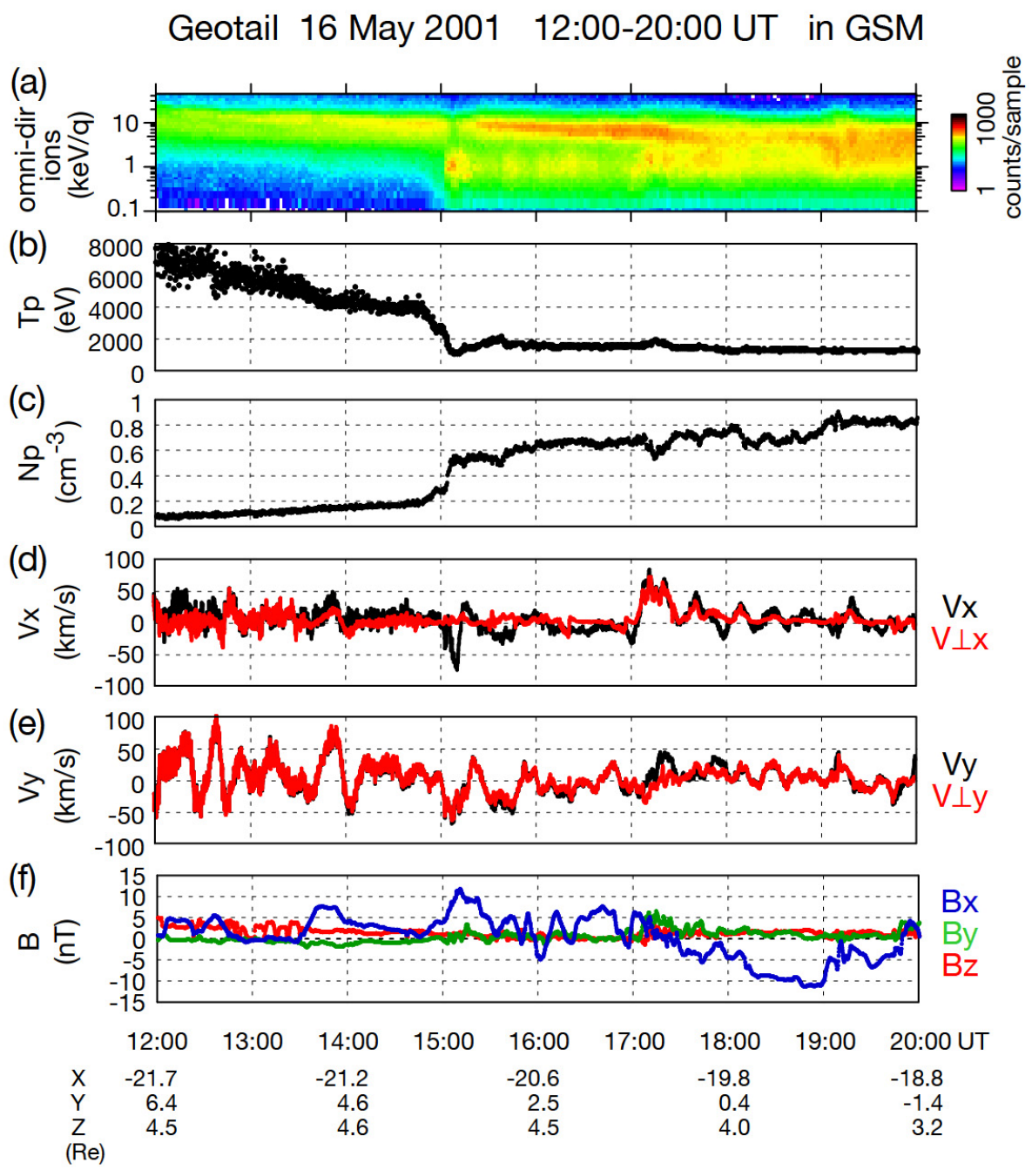

Fig. 1. Geotail observation between 12:00-20:00 UT on 16 May 2001. From the top, (a) energy-time (E-t) spectrogram of protons (omnidirectional summation of 2-D data) in $\mathrm{keV} / \mathrm{q}$, (b) proton temperature in $\mathrm{eV}$, (c) proton density in $\mathrm{cm}^{-3}$, (d, e) $X$ and $Y$ components of bulk velocity, and (f) three components of the magnetic field are shown. Bulk velocity is shown by black lines, and velocity perpendicular to the local magnetic field are shown by red lines. Locations of the spacecraft in the GSM coordinates are written at the bottom of the figure.

flowing plasma might be originated from the dusk lowlatitude boundary, transported into the midnight region in the Northern Hemisphere, cross the central plasma sheet, and turn back toward the dusk in the Southern Hemisphere.

We next examine the solar wind conditions for the event. Figure 2 shows the solar wind parameters for the day obtained by the ACE spacecraft, including the solar-wind traveling time of $50 \mathrm{~min}$ from the ACE location $\left(X \sim 229 R_{E}\right)$ to the Earth. From the top, (a) latitudinal angle of the IMF $\left(\theta_{\mathrm{IMF}}\right)$ in degree, (b) strength and the $Y$ and $Z$ components of the magnetic field in $\mathrm{nT}$, (c) proton density in $\mathrm{cm}^{-3}$, and (d) bulk flow speed in $\mathrm{km} / \mathrm{s}$ are shown. After an extended interval of predominantly southward IMF that lasted for more than $24 \mathrm{~h}$, the IMF pointed northward around 09:32 UT (the convection time included). The IMF became strongly north- ward $\left(\theta_{\mathrm{IMF}} \sim 53^{\circ}\right)$ for roughly $3 \mathrm{~h}$ between 11:20-14:30 UT with negative $B_{\mathrm{Y}}$. After a brief southward IMF interval between 14:33-14:49 UT, the IMF again directed strongly northward until 20:02 UT. There is a sudden increase in the proton density from $4 \mathrm{~cm}^{-3}$ to $6 \mathrm{~cm}^{-3}$ at 14:49UT. The solar wind speed was gradually decreasing, and it was about $480 \mathrm{~km} / \mathrm{s}$ around 15:00 UT when the two-component protons emerged (mentioned below). For simplicity, we fix the convection time to be $50 \mathrm{~min}$ in the analysis.

The time lag from the northward turning of the IMF (around 09:32 UT) to the emergence of the two-component protons (at 15:03 UT) is $5.5 \mathrm{~h}$. We also mention that the time lag from the beginning of the strongly northward IMF (around 11:20 UT) to the emergence of the two-component protons was $3.7 \mathrm{~h}$. The sudden increase in the solar wind 

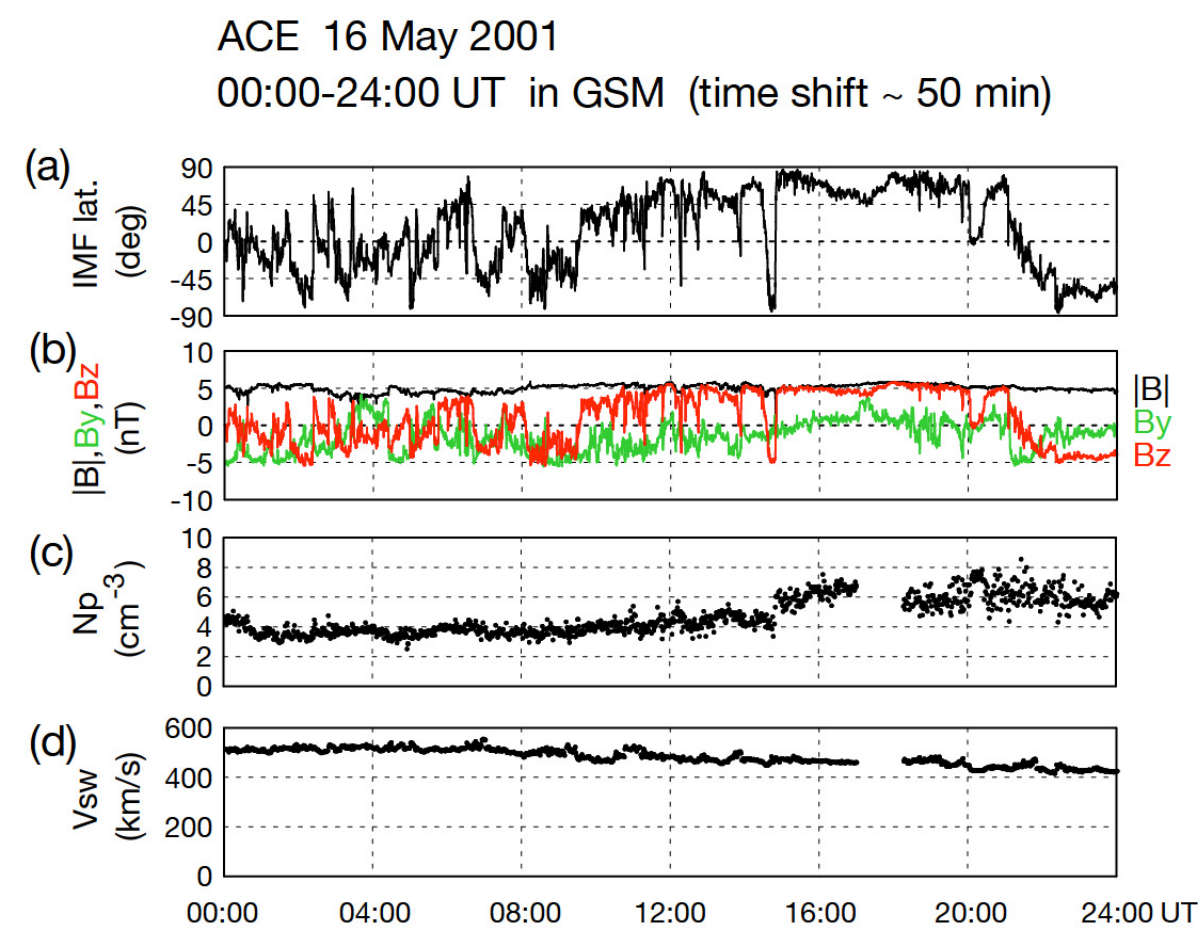

Fig. 2. ACE observation of the solar wind between 00:00-24:00 UT on 16 May 2001, including a time shift of 50 min from the ACE location to the Earth's magnetosphere. From the top, (a) latitudinal angle of the IMF $\left(\theta_{\mathrm{IMF}}\right)$, (b) strength and $Z$ component of the magnetic field, (c) proton density, and (d) bulk flow speed are shown.

density around 14:49 UT seems to coincide with the emergence of the two-component protons in the midnight plasma sheet. Compression of the magnetosphere by the increase in the solar wind dynamic pressure might change relative location of the Geotail spacecraft.

\subsection{May 1999 event}

We next study another event of the two-component protons in the midnight plasma sheet observed by the Geotail spacecraft on 29 May 1999. Figure 3 shows solar wind data from the ACE spacecraft (at $X \sim 225 R_{E}$ ) between 00:0018:00 UT in the same format as Fig. 2, including the convection time of $60 \mathrm{~min}$. The IMF pointed weakly northward from 22:42 UT of the previous day (data are not shown). After a southward IMF interval between 06:16-07:49 UT, the IMF pointed strongly northward $\left(\theta_{\mathrm{IMF}} \sim 62^{\circ}\right)$ between 08:04-08:56 UT, and it kept the northward direction since then $\left(\theta_{\mathrm{IMF}} \sim 46^{\circ}\right.$ between 08:56-12:40 UT). The proton density and the speed of the solar wind when the two-component protons (around 08:53-12:18 UT, discussed below) were observed were roughly $4-5 \mathrm{~cm}^{-3}$ and $410 \mathrm{~km} / \mathrm{s}$, respectively.

Figure 4 shows the Geotail data between 06:00-14:00 UT in the same format as Fig. 1. Before 06:40 UT Geotail was in the hot plasma sheet where the temperature and density of protons were $4 \mathrm{keV}$ and $0.2 \mathrm{~cm}^{-3}$. Around 06:40 UT the ion flux of medium energy range (around a few $\mathrm{keV}$ ) increased, and proton temperature ranged from 2 to $3 \mathrm{keV}$. Around 08:53 UT the cold proton component with the peak energy around $1 \mathrm{keV}$ was briefly observed, and proton temperature decreased to be $1.1 \mathrm{keV}$. Geotail was located at $(-14.6,5.8$, 2.2) $R_{E}$, staying in the southern plasma sheet where the magnetic field was about $(-8.1,6.0,7.2) \mathrm{nT}$. The cold component disappeared within a few min, but it again emerged around 09:18 UT and was continuously observed for $3 \mathrm{~h}$. In the plasma sheet with the two-component protons, plasma flows were quite stagnant $(<40 \mathrm{~km} / \mathrm{s})$. The observation of the twocomponent protons ended at 12:18 UT when Geotail was at $(-13.5,1.4,2.1) R_{E}$, in the middle of the strongly northward IMF interval.

The time lag from the beginning of the strongly northward IMF (around 08:04 UT) to the emergence of the twocomponent protons (08:53 UT) was as short as $50 \mathrm{~min}$. If we adopt the previous northward turning of the IMF (around 22:42 UT of the previous day), the time lag was as long as 10.2 $\mathrm{h}$. Although the passage of the southward IMF between 06:16-07:49 UT possibly gave rise to enhance transport of cold plasma in the tail (Nagai et al., 1998), no fast flow was detected at the Geotail location in this event. No sudden change in the solar wind flow was found when the twocomponent protons emerged. 
ACE 29 May 1999

00:00-18:00 UT in GSM (time shift $60 \mathrm{~min}$ )

(a)

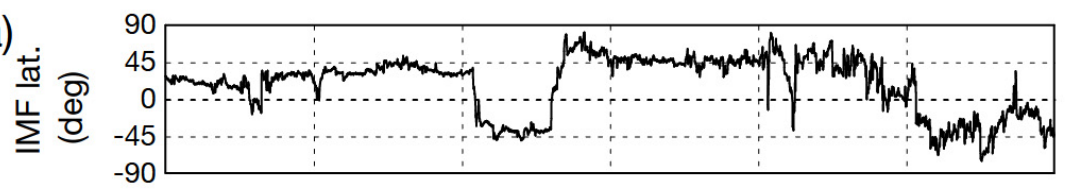

(b)

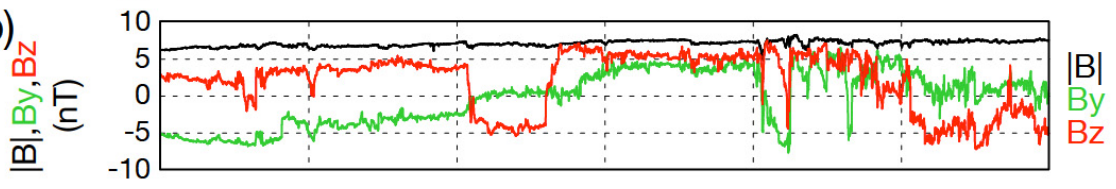

(c)

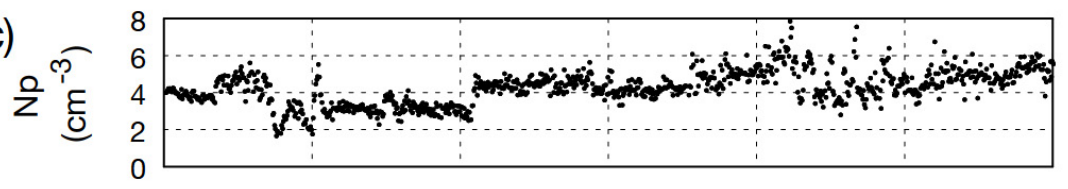

(d)

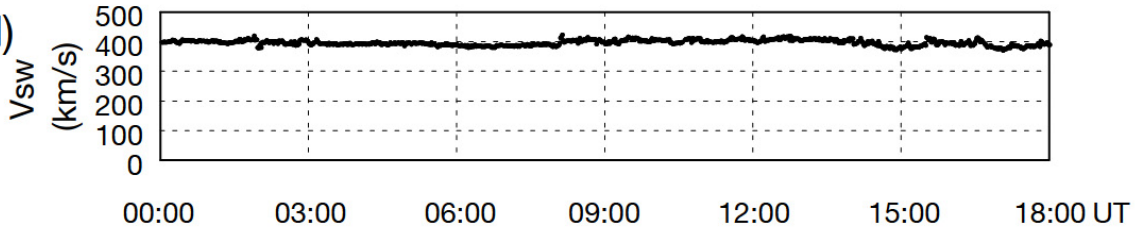

Fig. 3. ACE observation of the solar wind between 00:00-18:00 UT on 29 May 1999, with a time shift of 60 min, in the same format as Fig. 2.

We further investigate the two-component protons, since we have 3-D count data for the interval after 09:23 UT. Figure 5 expands the ion observations between 09:23-12:18 UT. From the top, (a) E-t spectrogram of omni-directional ions, (b) densities of the cold and hot components, (c) perpendicular and parallel temperatures of the cold component, (d) temperatures of the hot component, (e, f) $X$ and $Y$ components of the velocity of the cold component are shown. The perpendicular (parallel) temperature is shown by the green (blue) points, the density of the cold (hot) component is shown by the blue (red) points. As for the two-component protons, the density of the cold component $\left(0.4-0.7 \mathrm{~cm}^{-3}\right)$ dominated over that of the hot one $\left(0.3 \mathrm{~cm}^{-3}\right)$. The cold component went dawnward until 10:20 UT, while it went slightly duskward after 10:25 UT. After 11:00 UT bulk flows of the cold component were highly fluctuated.

We find that the cold proton component had a strong parallel anisotropy. The ratio of the perpendicular to parallel temperature of the cold component $\left(T_{\mathrm{C} \perp} / T_{\mathrm{C} \|}\right)$ was in the range of $0.4-0.7$. The perpendicular and parallel temperatures $\left(T_{\mathrm{C} \perp}\right.$ and $\left.T_{\mathrm{C} \|}\right)$ were $0.2-0.3 \mathrm{keV}$ and $0.4-0.6 \mathrm{keV}$, and those normalized by the kinetic energy of the solar wind protons $\left(E_{\mathrm{SW}} \sim 0.88 \mathrm{keV}\right)$ were roughly $0.2-0.3$ and $0.5-0.7$, respectively. The parallel temperature is higher than that in the dusk tail-flank cases (Nishino et al., 2007). The hot component was almost isotropic and its temperature gradually de- creased from $2.6 \mathrm{keV}$ to $1.8 \mathrm{keV}$. The decrease in the peak energy of the hot protons occurred during the extended northward IMF interval, as was seen in the previous event.

Figure 6 presents cuts of the ion PSD for the 12-s interval between 09:31:07-09:31:19 UT. The left panel (a) shows two-dimensional contour of the ion PSD in the plane that includes the local magnetic field. The maximum speed shown in the panel is $1920 \mathrm{~km} / \mathrm{s}$, and the magnetic field was $(-9.1$, 7.2, 7.2) nT in the GSM coordinates and shown as a red bar in the figure. An elongation of the PSD contours along the magnetic field is seen in the low-energy portion of the PSD (red-yellow colored region), while contours of the mediumto high-energy part are hardly elongated (green-blue colored region). The right panel (b) shows 1-D cuts of the PSD in the perpendicular (green) and parallel (blue) directions. Two red curves correspond to the one-count level of the detector. We can clearly see dominance of the parallel temperature over the perpendicular one.

\subsection{February 1995 event}

On 9 February 1995 an extended and strongly northward IMF occurred. Figure 7 shows solar wind data from the Wind spacecraft at $X \sim 193-194 R_{E}$, in the same format as Fig. 2. The plotted data includes the solar-wind convection time from the Wind location to the Earth's magnetosphere. As the solar wind speed gradually decreased through the 

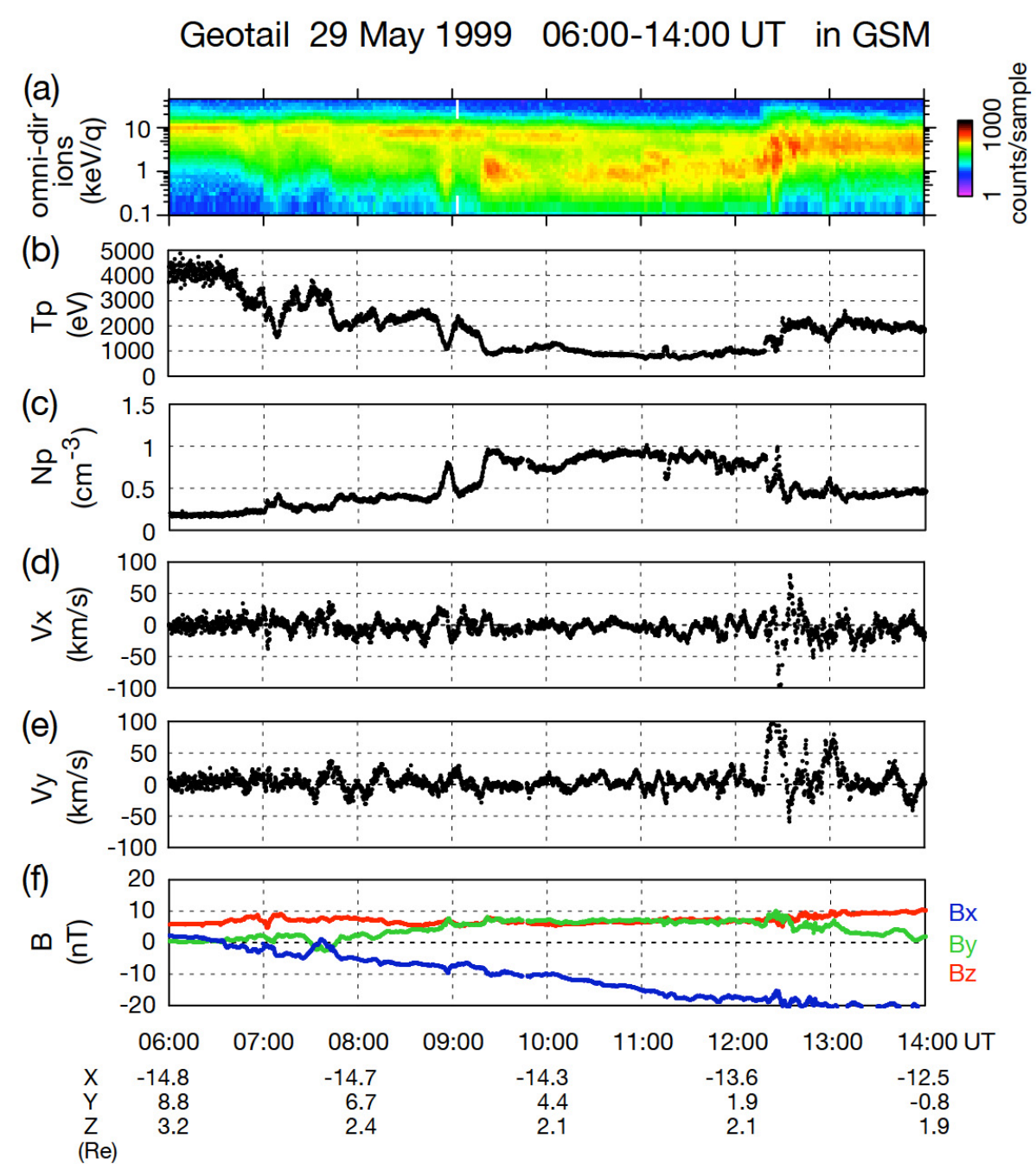

Fig. 4. Geotail observation between 06:00-14:00 UT on 29 May 1999, in the same format as Fig. 1.

day from $\sim 410 \mathrm{~km} / \mathrm{s}$ to $\sim 350 \mathrm{~km} / \mathrm{s}$, the convection time increased from $50 \mathrm{~min}$ to $58 \mathrm{~min}$. The density of the solar wind protons was about $5-10 \mathrm{~cm}^{-3}$. After a southward IMF interval between 02:52-04:40 UT (convection time of $50 \mathrm{~min}$ included), the IMF pointed northward and kept the polarity until the end of the day. After 04:40 UT the IMF was weakly northward $\left(\theta_{\mathrm{IMF}} \sim 30^{\circ}\right)$ until 12:00 UT, and it gradually increased to be $40^{\circ}$ until 14:30 UT. Around 14:30 UT the IMF became strongly northward $\left(\theta_{\mathrm{IMF}}>50^{\circ}\right)$, and the strongly northward IMF continued until the end of the day except a brief interval of weakly northward IMF around 16:20 UT. The IMF $B_{Y}$ was positive throughout the northward interval of our interest.

On the day Geotail was in the midnight region and observed two-component protons. Figure 8 shows Geotail observation for the latter half of the day (12:00-24:00 UT), in a similar format as Fig. 1 but the lowest energy shown in the E-t spectrogram of protons is about $0.02 \mathrm{keV}$. The arrival of the southward IMF around 02:52 UT led to an isolated substorm that started at 04:32 UT (Nagai et al., 1997), and Geotail observed fast flows $(>300 \mathrm{~km} / \mathrm{s})$ intermittently between 04:38-13:51 UT. Around 14:00 UT the fast flows ceased and the plasma sheet became quite stagnant. Between 14:00-15:23 UT the temperature and density of protons in the plasma sheet were roughly $1.5 \mathrm{keV}$ and $0.4 \mathrm{~cm}^{-3}$, respectively. Around 15:23 UT low-energy protons whose energy were $0.05-0.5 \mathrm{keV}$ was observed for a brief interval, and such low-energy component was intermittently observed with dawnward flows $\left(V_{Y} \sim-30 \mathrm{~km} / \mathrm{s}\right)$ until 16:40 UT. Around 16:44 UT the count of the low-energy protons increased and two-component protons began to be observed (Fig. 8a) when Geotail was located at $(-26.1,-1.6$, -2.6) $R_{E}$ and moving relatively to the high-latitude portion of the southern plasma sheet. The emergence of the 


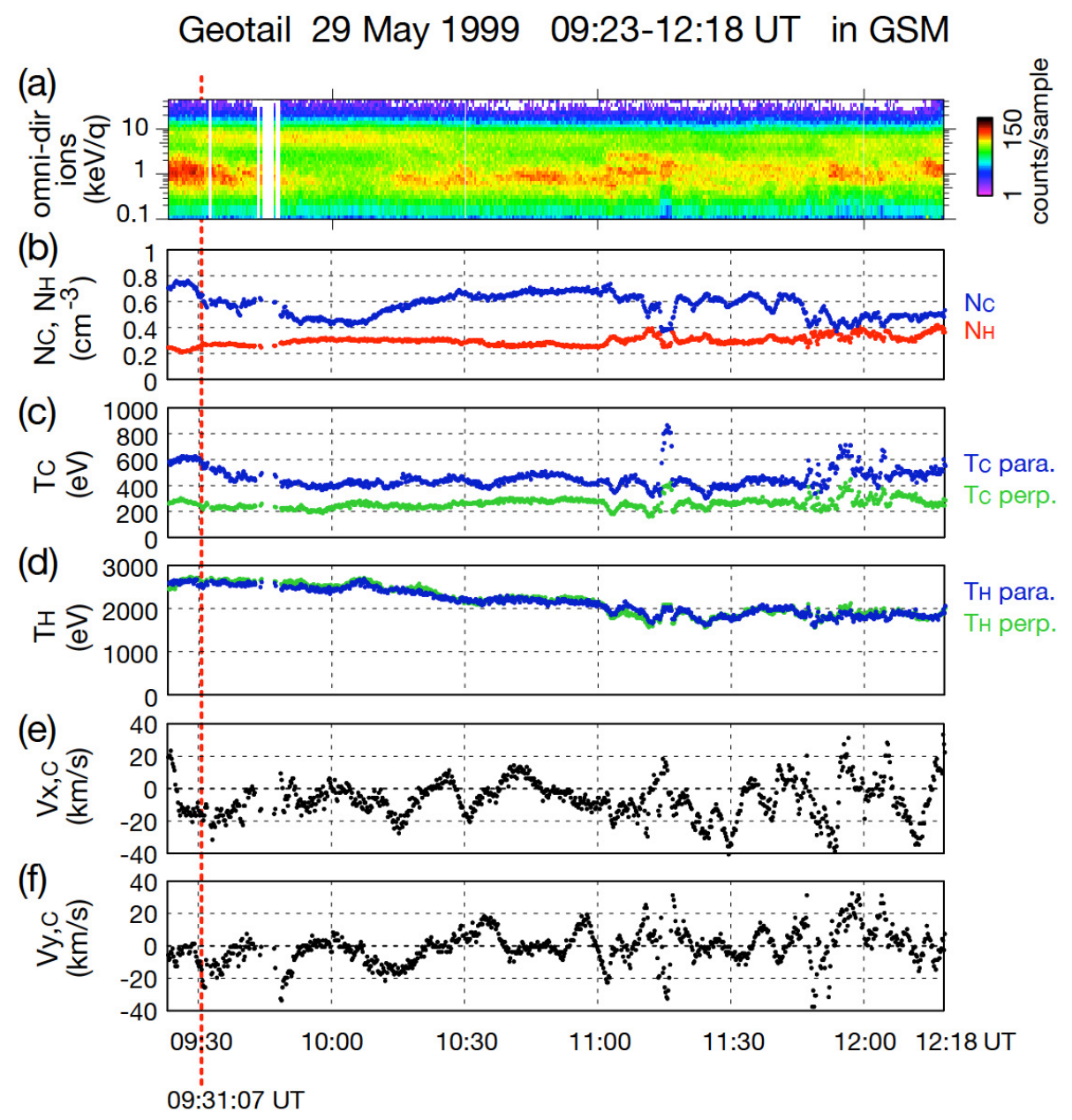

Fig. 5. Expansion of the Geotail observations between 09:23-12:20 UT during which the two-component protons were observed and the 3-D count data exist. From the top, (a) E-t spectrogram of omni-directional ions, (b) densities of the cold and hot components, (c) perpendicular and parallel temperatures of the cold component, (d) temperatures of the hot component, (e, $\mathbf{f}) X$ and $Y$ components of the velocity of the cold component are shown. The perpendicular (parallel) temperature is plotted by the green (blue) points, and the density of the cold (hot) component is done by the blue (red) points.

two-component protons was accompanied by a dawnward flow $\left(V_{\mathrm{Y}} \sim-40 \mathrm{~km} / \mathrm{s}\right)$. The two-component protons were observed until 00:20 UT of the following day except for short intervals. The temperature of protons from moment calculations were $0.6-0.7 \mathrm{keV}$. The proton density was $0.7 \mathrm{~cm}^{-3}$ for the initial period of the two-component proton observation between 16:44-17:52 UT, and it increased to be $1.1 \mathrm{~cm}^{-3}$ after 18:30 UT.

We examine the emergence condition of the twocomponent protons in this event. The time lag from the northward turning of the IMF to the emergence of the two-component protons in the midnight plasma sheet was as long as $12 \mathrm{~h}$. We note that the emergence (16:44 UT) occurred $2.2 \mathrm{~h}$ after the arrival of the strongly northward IMF (14:30 UT). The speed of the dawnward flow observed around the initial period of the two-component protons was about $40 \mathrm{~km} / \mathrm{s}$, with which it takes about $70 \mathrm{~min}$ to transport plasma from the dusk flank to the Geotail location.

Since 3-D data of proton distribution function are available for this event (until 20:30 UT), we proceed to further analysis of the two-component protons, separating the cold and hot components by the two-Maxwellian mixture model (Ueno et al., 2001). Figure 9 expands the Geotail observation for the 4-h interval between 16:30-20:30 UT, in a similar format as Fig. 5 but the lowest energy of the protons presented in the E-t spectrogram is about $0.02 \mathrm{keV}$. We have calculated moment parameters of the two components for the interval when two components are apparent in count (i.e. 16:44-17:52 UT and 18:31-20:30 UT). The density of the hot component was $0.2-0.3 \mathrm{~cm}^{-3}$ throughout the two-component interval, and that of the cold component increased from $\sim 0.4 \mathrm{~cm}^{-3}$ to $\sim 0.7 \mathrm{~cm}^{-3}$. 


\section{Ion PSD \\ 29 May 1999 09:31:07-09:31:19 UT}

(a) 2D contour

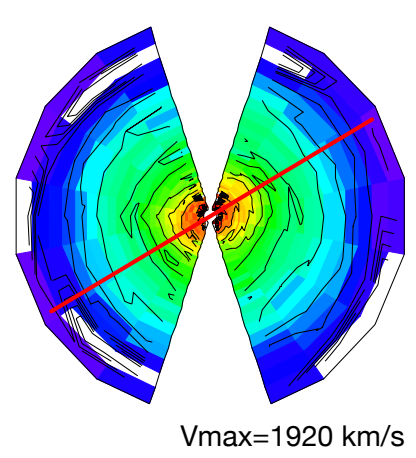

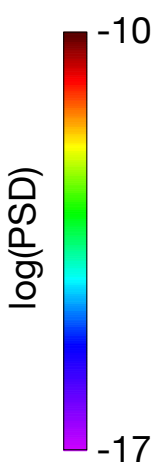

(b) $1 \mathrm{D}$ cuts

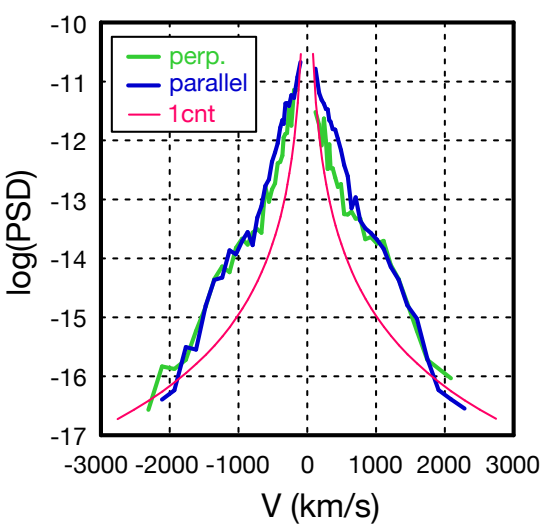

Fig. 6. Cuts of ion phase space density (PSD) for the 12-s interval between 09:31:07-09:31:19 UT on 29 May 1999. The left panel (a) shows the contour of the PSD in the plane that includes the local magnetic field which is shown as a red bar in the figure. The right panel (b) presents one-dimensional cuts of the ion PSD. The green (blue) line shows the PSD in the direction perpendicular (parallel) to the magnetic field. Two red curves correspond to the one count level of the detector.

Wind 9 February 1995

00:00-24:00 UT in GSM (convection time included)

(a)

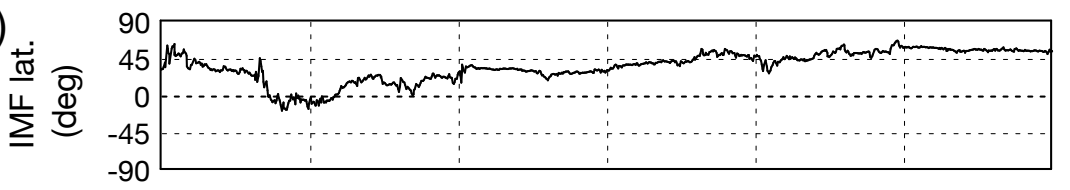

(b)

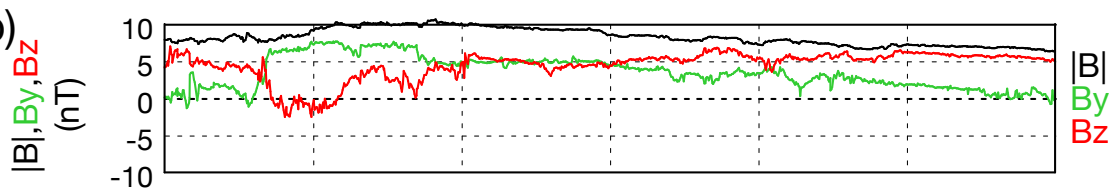

(c)

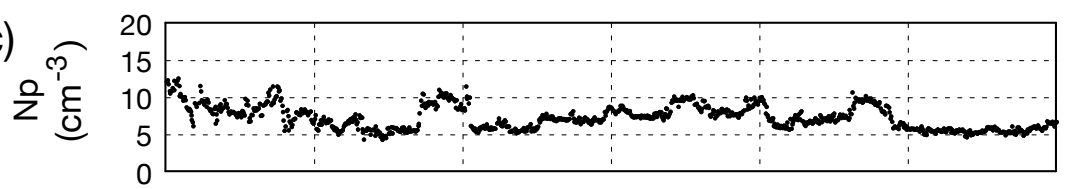

(d)

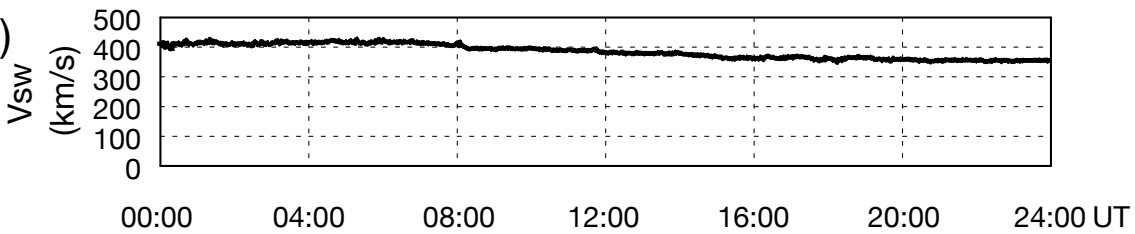

Fig. 7. Wind observation of the solar wind between 00:00-24:00 UT on 9 February 1995, in the same format as Fig. 2 . The time is shifted from the Wind location to the Earth's magnetosphere.

For the initial period of the two-component proton observation between 16:44-17:52 UT, the averaged den- sities of the cold and hot components were 0.38 and $0.29 \mathrm{~cm}^{-3}$, respectively. The cold proton component had 

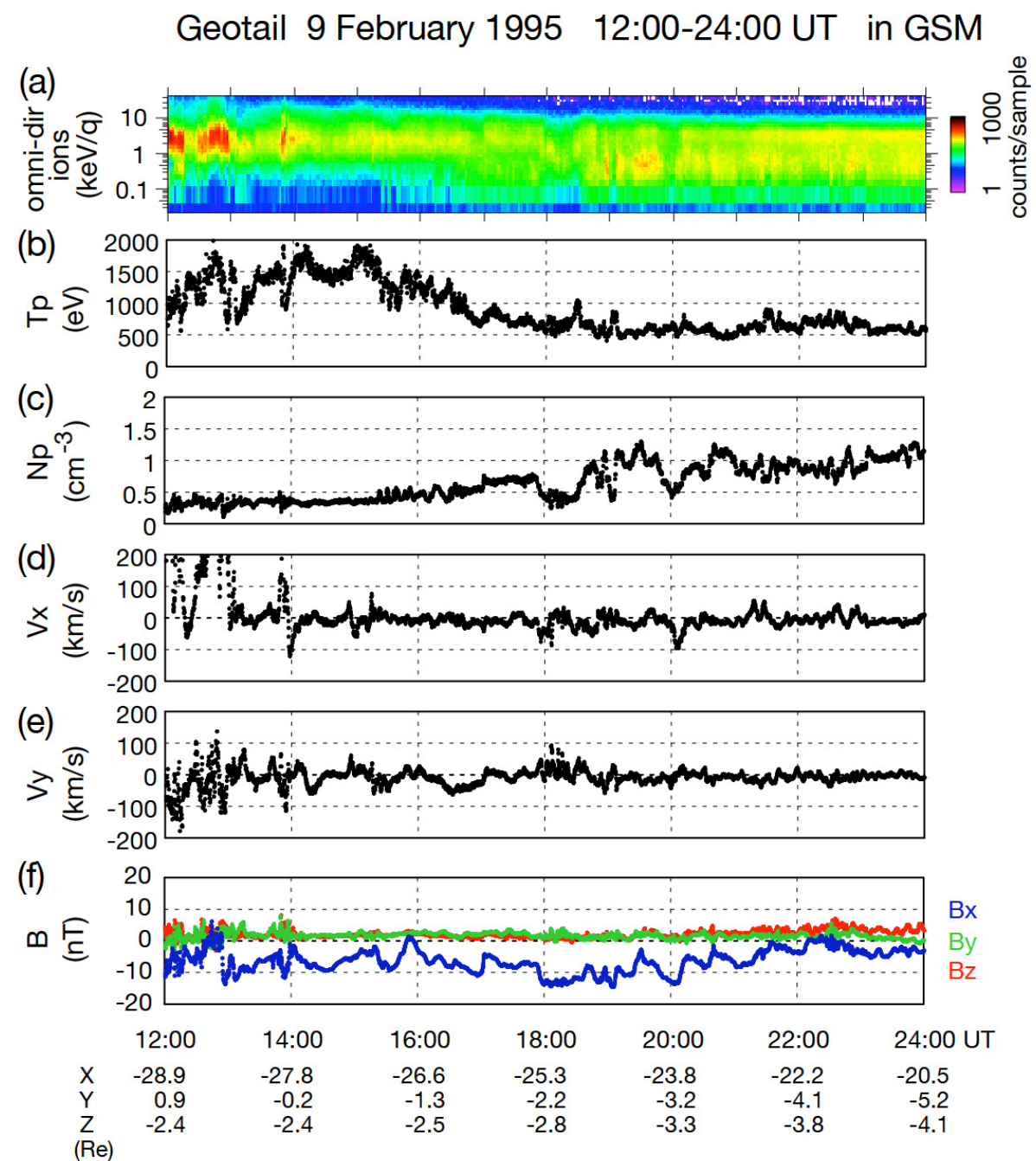

Fig. 8. Geotail observation between 12:00-24:00 UT on 9 February 1995, in the same format as Fig. 1.

a parallel anisotropy $\left(T_{\mathrm{C} \perp} / T_{\mathrm{C} \|} \sim 0.67\right)$, where $T_{\mathrm{C} \perp}$ and $T_{\mathrm{C} \|}$ were $130 \mathrm{eV}$ and $190 \mathrm{eV}$, and those normalized by $E_{\mathrm{SW}}$ $(\sim 0.68 \mathrm{keV})$ were 0.19 and 0.28 , respectively. After an excursion to the high-latitude part of the southern plasma sheet between 17:45-18:30 UT, Geotail again approached the central plasma sheet and observed the two-component protons. The density of the cold component $\left(\sim 0.7 \mathrm{~cm}^{-3}\right)$ was higher than that observed during the previous stay. After 19:33 UT a strong parallel anisotropy of the cold component was again observed $\left(T_{\mathrm{C} \perp} / T_{\mathrm{C} \|} \sim 0.6\right)$. In contrast to the cold component with a strong parallel anisotropy, the hot component was isotropic, and its temperature was about $1.5 \mathrm{keV}$ throughout the intervals of our interest.

\section{Superposed analysis}

In order to further investigate the two-component protons in the midnight plasma sheet, we surveyed the Geotail E-t spectrograms of protons by eyes between 1995-2003, and picked up the proton data with two peaks in count. The criteria for the midnight plasma sheet are as follows:

$-10>X>-30 R_{E}$

$\left|Y_{\mathrm{GSM}}\right|<10 R_{E}$

$\beta>0.5$

In this paper we concentrate on the events with twocomponent interval longer than $1 \mathrm{~h}$. The condition for $\beta$ (the ratio of proton thermal to magnetic pressure) is to exclude data of the plasma sheet boundary layer. We find 5 events 

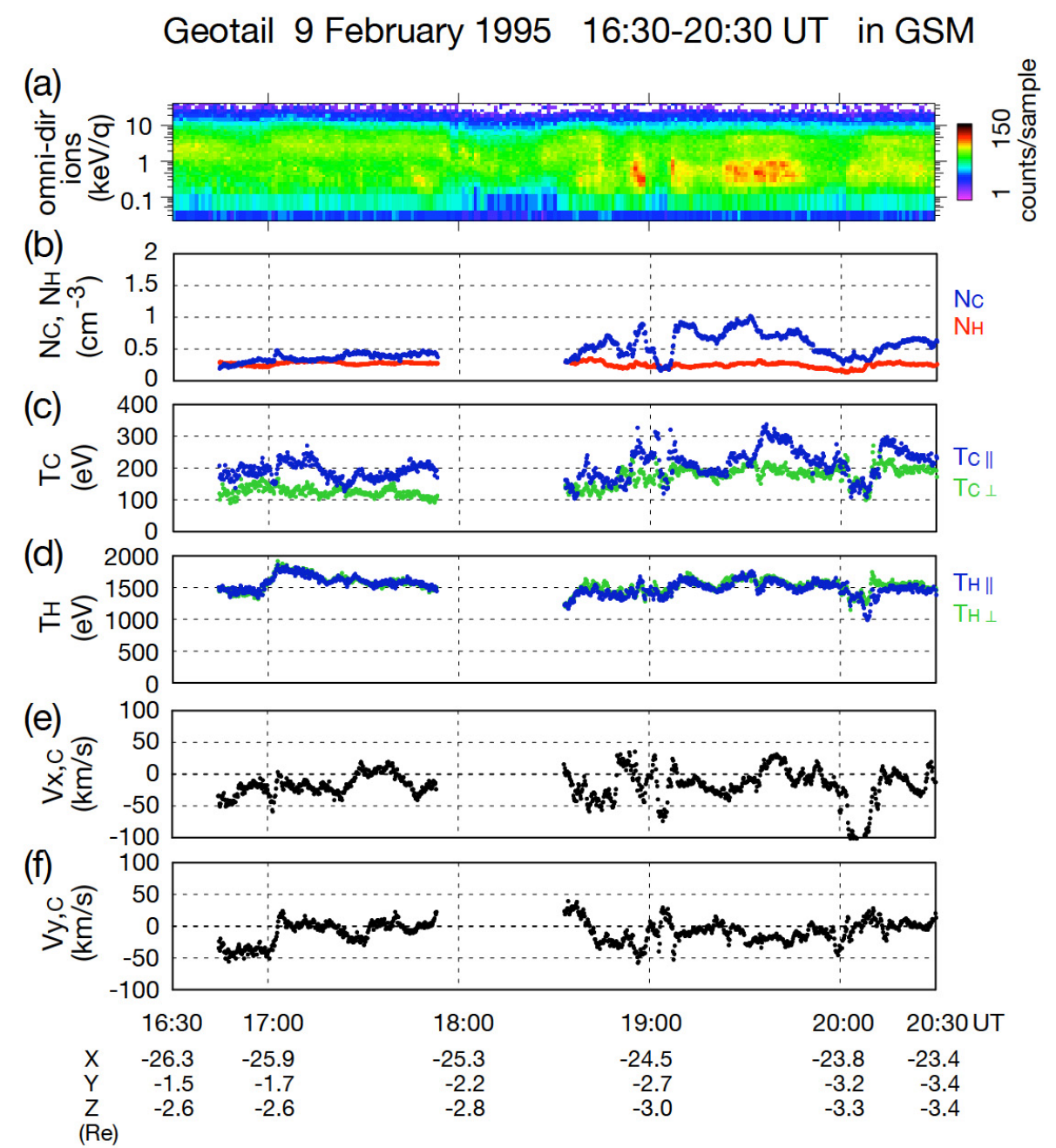

Fig. 9. Expansion of the Geotail observation between 16:30-20:30 UT, in the same format as Fig. 5.

that include 3 cases studied above, which are listed in Table 1.

Figure 10 shows projection onto the GSM- $X Y$ plane of observed locations of the two-component proton events. The symbols in the figure $(a, b, \ldots, e)$ correspond to events listed in Table 1. The dotted curve shows the averaged location of the magnetopause calculated with a model by Roelof and Sibeck (1993), and data in the gray-hatched region are out of survey in this paper.

\subsection{Solar wind conditions}

We superpose solar wind parameters of the 5 events in Fig. 11, where time series of the latitudinal angle of the IMF (a) and the proton density (b) are shown. The zero $\left(t_{\mathrm{SW}}=0\right)$ is set to the beginning of the two-component proton observation in the midnight plasma sheet, and data for 18-h interval between $t_{\mathrm{SW}}=-12 \mathrm{~h}$ and $t_{\mathrm{SW}}=6 \mathrm{~h}$ are shown. All of
5 events occurred under the strongly northward IMF condition $\left(\theta_{\mathrm{IMF}}>45^{\circ}\right)$. The two-component protons began to be observed within $3 \mathrm{~h}$ after the arrival of the strongly northward IMF. Although 2 events occurred during the extended northward IMF interval that lasted for more than $10 \mathrm{~h}$, the two-component protons were not observed under prolonged but weakly northward IMF conditions. In one event (16 May 2001) a sudden increase in the solar wind density might lead to dawnward flows in the midnight region as well as relative satellite motion, through transformation of the magnetosphere by the sudden compression. However, the increase in the solar wind density is not the necessary condition for plasma transport from the dusk flank to the midnight region, because other 4 events were not accompanied by increases in the solar wind density. In another event (16 June 2003) a sudden decrease in density occurred just before the emergence of the two-component protons. The solar wind speed had a wide variation between $285 \mathrm{~km} / \mathrm{s}$ and $520 \mathrm{~km} / \mathrm{s}$ in the 5 
Table 1. Two-component proton events found in the midnight region. In the column of the anisotropy, "N/A" is the abbreviation for "not available". As for hemispheres, S and N represents the Southern and Northern Hemispheres, respectively. The hemisphere where the two-component protons were initially observed is focused on.

\begin{tabular}{cccccc}
\hline Event & Date & UT & Location (start) & IMF BZ & anisotropy \\
\hline (a) & 9 Feb 1995 & $17: 01-24: 20$ & $(-24.2,-2.9,-3.2)$ & prolonged, strong N & weakly parallel \\
(b) & 8 March 1998 & $17: 10-18: 55$ & $(-21.8,-3.7,-1.3)$ & prolonged, strong N & isotropic \\
(c) & 29 May 1999 & $08: 53-12: 18$ & $(-14.6,5.8,2.2)$ & strong N & strongly parallel \\
(d) & 16 May 2001 & $15: 03-19: 00$ & $(-20.9,3.5,4.6)$ & strong N & N/A \\
(e) & 16 June 2003 & $06: 16-08: 40$ & $(-22.4,8.2,1.3)$ & strong N & N/A
\end{tabular}

\begin{tabular}{cccc}
\hline event & IMF $B_{Y}$ & hemisphere & etc. \\
\hline (a) & + & $\mathrm{S}$ & \\
(b) & + & $\mathrm{S}$ & \\
(c) & + & $\mathrm{S}$ & \\
(d) & - & $\mathrm{N}$ & $N_{\mathrm{SW} \text { increase }}$ \\
(e) & + & $\mathrm{S}$ & $N_{\mathrm{SW}}$ decrease \\
\hline
\end{tabular}

events, while no sudden change in the speed occurred (data are not shown).

\subsection{Signatures of the two-component protons}

Figure 12 shows superposed plots of the time series of the plasma sheet parameters of the 5 events. From the top, (a) proton density, (b) proton temperature, (c) $V_{\mathrm{X}}$, (d) $V_{\mathrm{Y}}$, (e) latitudinal angle of the magnetic field, (f) $B_{X}$ are shown. The zero of the horizontal axis $\left(t_{\mathrm{PS}}\right)$ corresponds to the beginning of the two-component proton observation at the Geotail location in each event, and data for 1-h interval between $t_{\mathrm{PS}}=-30 \mathrm{~min}$ and $t_{\mathrm{PS}}=30 \mathrm{~min}$ are presented. Increase in proton density (Fig. 12a) and decrease in proton temperature (Fig. 12b) around $t_{\mathrm{PS}}=0$ are due to emergence of the twocomponent protons.

\subsubsection{Plasma flows}

The plasma flows in the cold plasma sheet were quite stagnant and the averaged flow directions pointed dawnward. Especially, emergence of the two-component protons were accompanied by the dawnward flows $(-20 \sim-70 \mathrm{~km} / \mathrm{s})$ in 4 events (event a, b, d, e). However, bulk flows were at times highly fluctuated and even went duskward.

\subsubsection{Latitude}

In 4 events (event a, c, d, e), emergence of the twocomponent protons was accompanied by decrease in the latitudinal angle of the local magnetic field (Fig. 12e), which means that the two-component protons began to be observed at the higher-latitude portion of the plasma sheet. In 1 event (event b), the two-component protons emerged without decrease in the latitudinal angle of the local magnetic field.

\section{Locations of the two-component events}

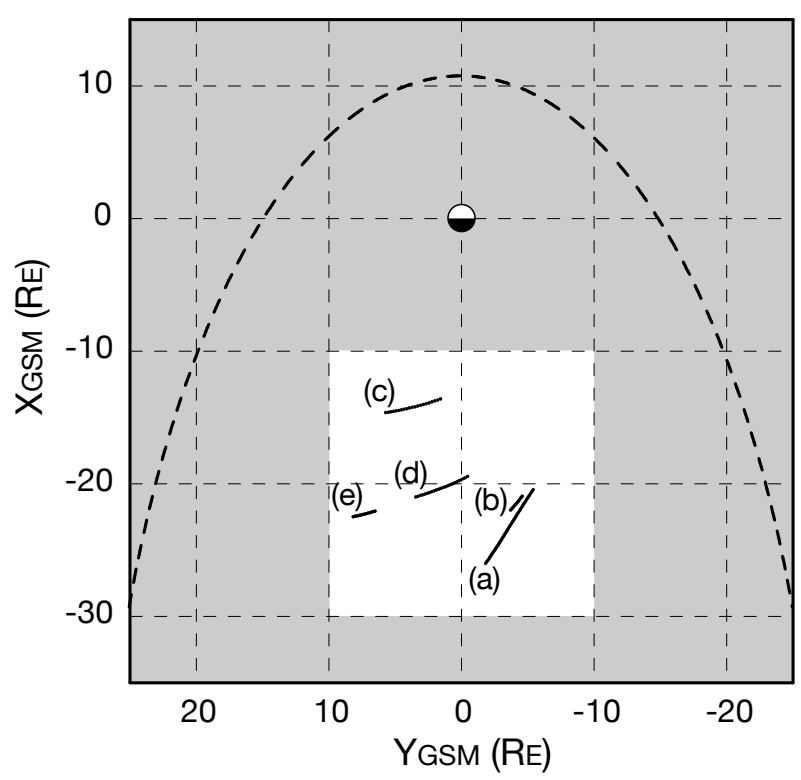

Fig. 10. Observed locations of the two-component proton events in the midnight plasma sheet. Projection onto the GSM- $X Y$ plane is shown. A dotted curve in the figure shows the averaged location of the magnetopause calculated with a model by Roelof and Sibeck (1993).

\subsubsection{Anisotropies}

In 3 events we have 3-D distribution function with which we examine temperature anisotropies of the cold and hot components. In 2 of the 3 events (event a, c) the cold component 


\section{Solar wind conditions for 5 events}
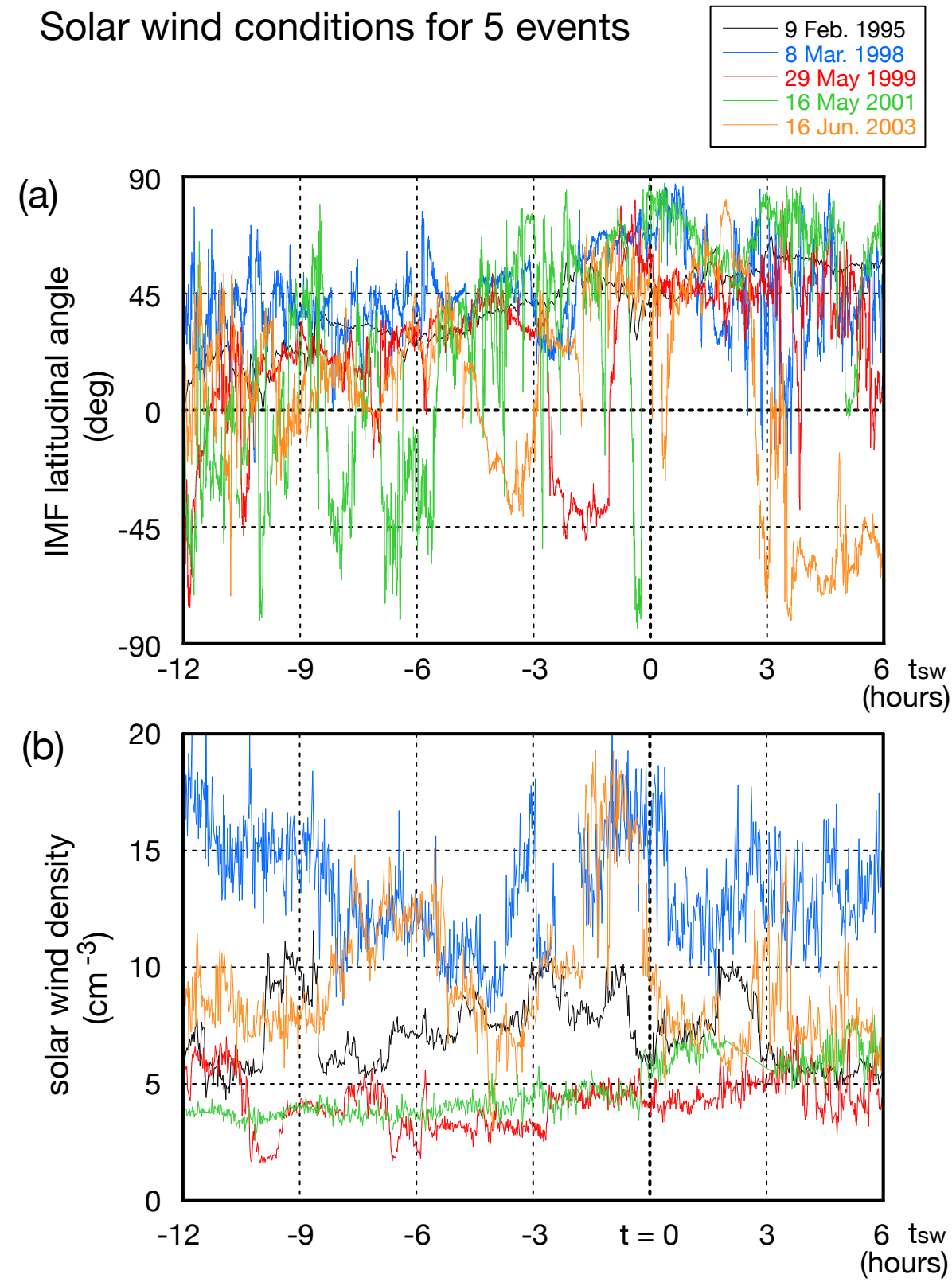

Fig. 11. Superposed plots of the solar wind parameters for the 5 events. The upper panel (a) shows the latitudinal angle of the IMF, and the lower one (b) does the density of the solar wind protons. The zero of the horizontal axis $\left(t_{\mathrm{SW}}\right)$ corresponds to the emergence of the two-component protons.

had a parallel anisotropy, and in 1 event (event b) it was isotropic. The hot component was almost isotropic in all of the 3 events. These features resemble those observed in the tail-flank plasma sheet near the dusk low-latitude boundary, where the cold component of the two-component protons at times has a parallel anisotropy while the hot one is less anisotropic (Nishino et al., 2007).

\subsubsection{Hot proton component}

The hot component temperatures normalized by $E_{\mathrm{SW}}$ were 2-3, which was lower than that of the dusk tail flank cases (3-4). In 3 events (event c, d, e), the peak energy of the hot proton component gradually decreased during prolonged northward IMF intervals, which is equivalent to decrease in the hot component temperatures. The observed gradual cooling of the midnight plasma sheet is consistent with the in-situ 


\section{Plasma sheet parameters for 5 events}
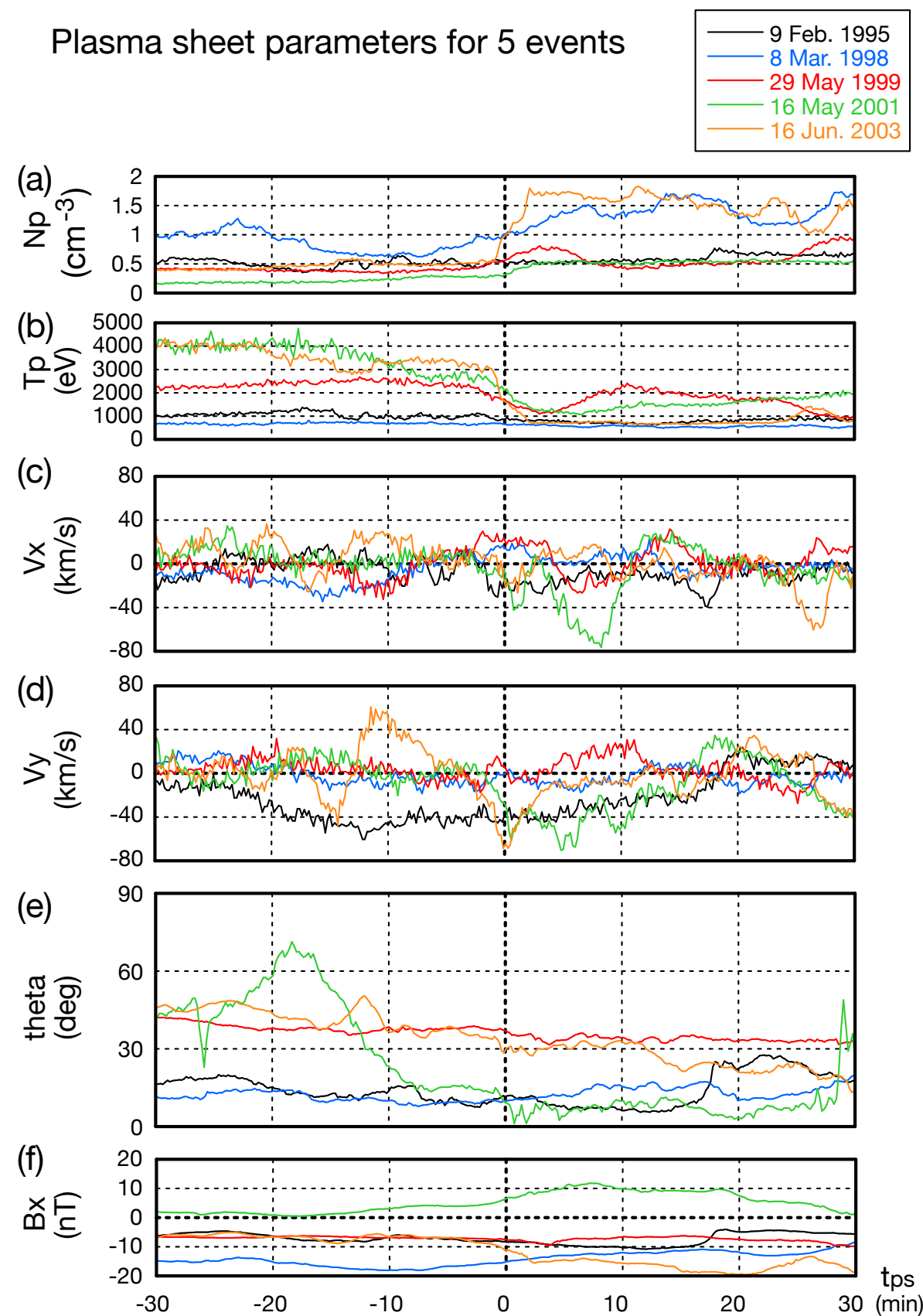

Fig. 12. Superposed plots of the plasma sheet parameters for the 5 events. From the top, (a) proton density, (b) proton temperature, (c) $V_{X}$, (d) $V_{\mathrm{Y}}$, (e) latitudinal angle of the magnetic field, (f) $B_{\mathrm{X}}$ are shown. The zero of the horizontal axis $\left(t_{\mathrm{PS}}\right)$ corresponds to the emergence of the two-component protons.

observations on the duskside (Øieroset et al., 2005) as well as remote-sensed observations from low altitude satellites in both flanks (Wing et al., 2006). In other 2 events (event a, b), gradual decrease in the hot proton component was not observed, where the hot component temperature was as low as $1.5 \mathrm{keV}$.

\subsection{Hemisphere}

When the two-component protons were observed, Geotail was located in the Southern Hemisphere $\left(B_{\mathrm{X}}<0\right)$ for the positive IMF $B_{Y}$ cases, while it was in the Northern Hemisphere $\left(B_{X}>0\right)$ for the negative IMF $B_{Y}$ case (Table 1). Figure 13 shows a schematic view of lobe-cell circulations and 


\section{Proposed scenario for dusk-to-midnight flow generation under strongly northward IMF}

(a) IMF By<0

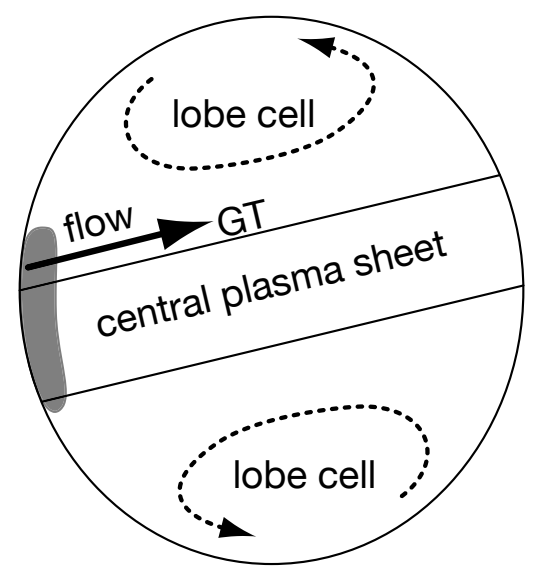

two-component protons on the duskside

GT : Geotail location

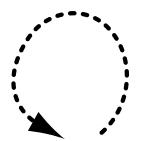

lobe cell circulation (b) IMF By>0
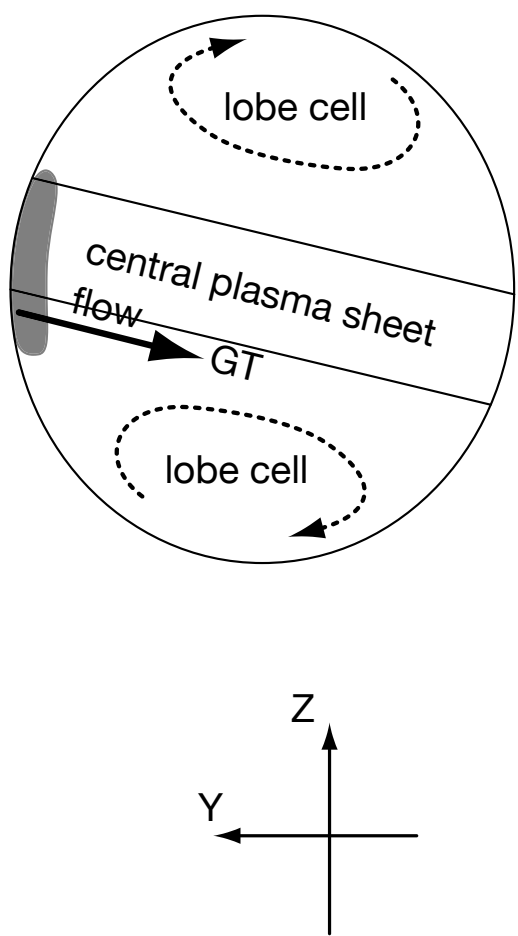

viewed from the tail

Fig. 13. A schematic view of the proposed scenario for generation of the dusk-to-midnight plasma flows in the high-latitude region of the plasma sheet. Cuts of the magnetotail for (a) neagtive and (b) positive IMF $B_{Y}$ cases are presented. The arrows with dotted curves show the lobe cell circulations whose sense depends on the IMF $B_{Y}$. The abbreviation "GT" shows the plausible spacecraft locations, and the black arrows correspond to the expected dusk-to-midnight (dawnward) flows. Twisting of the plasma sheet that depends on the IMF $B_{\mathrm{Y}}$ (Maezawa and Hori, 1998) is also represented in the figure.

dusk-to-midnight (dawnward) flows under strongly northward IMF. The direction of the lobe-cell circulation under northward IMF depends on the sign of the IMF $B_{Y}$ (e.g. Reiff and Burch, 1985), and panels (a) and (b) represent the negative and positive $B_{Y}$ cases, respectively. In all of 5 events, the two-component protons were observed in the hemisphere where the circulation on the plasma sheet side of the lobe cell goes toward the dusk-to-midnight direction.

\section{Discussion}

We have reported that the two-component protons were observed in the midnight plasma sheet under northward IMF. Since the two-component protons are frequently observed on the duskside but hardly on the dawnside, we suggest that the source of the two-component protons found in the midnight region is the duskside magnetopause. In 4 events, the start of the two-component proton observation was accompanied by dawnward flows (discussed later), which also supports the idea that the two-component protons move from the dusk flank to the midnight region. However, bulk plasma flows were highly fluctuated and at times went duskward.

We compare anisotropies of the two-component protons in the midnight plasma sheet with those in the dusk flank plasma sheet. Nishino et al. (2007) analyzed the twocomponent protons in the dusk plasma sheet near the lowlatitude boundary and found that the cold proton component has a parallel anisotropy $\left(T_{\mathrm{C} \perp} / T_{\mathrm{C} \|}<1\right)$ in the tail flank region while it has a perpendicular anisotropy $\left(T_{\mathrm{C} \perp} / T_{\mathrm{C} \|}>1\right)$ on the 
dayside. In the present study we have found that the cold proton component in the midnight region possesses at times a parallel anisotropy. The sense of the anisotropy of the cold proton component in the midnight region is same as that of tail flank plasma sheet in the dusk low-latitude boundary, and it is different from that on the dayside. The isotropic distribution function of the hot proton component in the midnight region also resembles that in the dusk tail flank. We therefore conclude that the origin of the two-component protons in the midnight region is the dusk tail-flank plasma sheet.

Let us compare the cold proton component in the midnight region with that in the dusk tail-flank region. In the event on 29 May 1999, normalized parallel temperature of the cold component $\left(T_{\mathrm{C} \|} / E_{\mathrm{SW}} \sim 0.5-0.7\right)$ was higher than that in the dusk tail-flank region $(0.2-0.4)$ obtained in a statistical study by Nishino et al. (2007). We therefore suggest that some heating process may work on the cold component on the way from the dusk flank to the midnight region, while we could not conclude it because we do not have data of the plasma sheet near the dusk low-latitude boundary on the day and cannot directly compare the dusk and midnight regions.

On the other hand, normalized temperatures of the hot proton component in the midnight region $\left(T_{\mathrm{H}} / E_{\mathrm{SW}} \sim 2-3\right)$ are, statistically, lower than those in the dusk flank plasma sheet (3-4 (Nishino et al., 2007)). The difference between the hot component temperature in the midnight and that in the dusk flank may be partly due to spatial gradient of the temperature (Wing et al., 2005), and partly due to gradual cooling of the plasma sheet during prolonged northward IMF intervals. In 3 events, gradual decrease in the peak energy of the hot proton component was observed. Since gradual cooling of the plasma sheet occurs in the flanks (Wing et al., 2006) as well as on the duskside (Øieroset et al., 2005) under northward IMF, our observations in the midnight region suggest that cooling of the hot plasma sheet under northward IMF is a global phenomenon in the near-Earth magnetotail. Additionally, results of previous studies of the plasma sheet using the moment parameters (e.g. Baumjohann, 1993; Terasawa et al., 1997) do not necessarily mean solar wind entry thereto but might show cooling of the plasma sheet.

In other 2 events, gradual cooling was not observed for the intervals of our interest. These two events occurred under extended $(>10 \mathrm{~h}$ ) northward IMF, and there the hot component temperature was as low as $1.5 \mathrm{keV}$ from the beginning of the two-component proton observation. The fact that the hot component temperature was nearly constant and relatively low may suggest existence of a lower limit of the hot component temperature, as was also implied by Wing et al. (2006). Terasawa et al. (1997) showed that response time of the plasma sheet to the solar wind parameters during northward IMF is as long as $9 \mathrm{~h}$, suggesting a diffusion-like transport from the flanks to the midnight region. However, the long time lag presented by their study might correspond to time scale of the plasma sheet cooling.
Let us consider the emergence condition of the twocomponent protons in the midnight region. In all of the 5 events the observation of the two-component protons started within $3 \mathrm{~h}$ after the strongly northward IMF arrived at the Earth's magnetosphere. Two events occurred without extended northward interval; the two-component protons emerged 3-6h after the northward turning of the IMF. Although two events in our study were observed during very extended northward IMF intervals $(>10 \mathrm{~h}$ ), the two-component protons were not observed during weakly northward IMF but found after the strongly northward IMF passed by the magnetosphere. We conclude that the condition for the two-component proton emergence in the midnight region is strongly northward IMF $\left(\theta_{\mathrm{IMF}}>45^{\circ}\right)$ which continues for a few $h$. The relatively short time scale is sufficient for the plasma transport from the dusk flank to the midnight region, because it takes about $1-2 \mathrm{~h}$ with the observed dawnward flows $(-20 \sim-70 \mathrm{~km} / \mathrm{s})$.

We discuss the relation between previous observations under strongly northward IMF and what we have found in the present study. Studying the dusk low-latitude boundary under strongly northward IMF, Fairfield et al. (2000) mentioned that wavy structures observed in the dusk tail flank were attributed to the Kelvin-Helmholtz (KH) instability which can play an important role in plasma transport across the magnetopause as well as in mixing of the solar wind and the magnetospheric plasma. In addition, Nishino et al. (2007) discussed that the parallel anisotropy of the cold proton component on the duskside might be explained by magnetic reconnection in the KH vortices. Although apparent vortical structures by the $\mathrm{KH}$ instability exist only in the region within a few $R_{E}$ from the magnetopause (Hasegawa et al., 2006), highly fluctuated bulk plasma flows might transport the cold plasma from the dusk flank to the midnight region.

Another mechanism that is believed to occur under strongly northward IMF is double high-latitude reconnection on the dayside (e.g. Song and Russell, 1992; Li et al., 2005; Øieroset et al., 2005). According to the double-lobe reconnection model, the solar wind flux trapped onto the dayside magnetosphere goes down to the tail region, and the cold plasma sheet can form in the midnight region as well. However, the cold proton component on the dayside has a perpendicular anisotropy (Nishino et al., 2007), which disagrees with the parallel anisotropy observed in the midnight region. Therefore, double high-latitude reconnection, although it may actually take place (Onsager et al., 2001; Lavraud et al., 2005, 2006), does not seem to directly contribute to refilling of the midnight plasma sheet.

The observed locations of the two-component protons can be a clue to understand transport paths. In 4 events the cold component started to be observed at the high-latitude portion of the plasma sheet. This feature is consistent with previous observations of the cold plasma in the near-Earth magnetotail under northward IMF; Zwolakowska et al. (1992) showed that the cold plasma is observed in the high-latitude portion 
of the near-Earth magnetotail, and Phan et al. (1998) showed that the cold plasma in the flank plasma sheet starts to be observed in the high-latitude regions. Keeping in mind these previous observations, we suggest that the two-component protons move in the high-latitude portion of the plasma sheet from the dusk flank to the midnight region.

Finally, we consider generation mechanism of the duskto-midnight plasma flows under strongly northward IMF. We have found that the two-component protons were observed in the hemisphere where the circulation on the plasma sheet side of the lobe cell goes toward the dusk-to-midnight direction (Fig. 13). We propose that viscous interaction between the high-latitude portion of the plasma sheet and the lobe cell generates the dusk-to-midnight flows in one hemisphere. The other hemisphere was not observed by Geotail for all events in the present study, which is possibly due to plasma sheet twisting whose sense depends on the sign of the IMF $B_{Y}$ (Maezawa and Hori, 1998). In future works, multi spacecraft observations as well as ground observations will help us understand plasma transport paths in the near-Earth magnetotail under strongly northward IMF.

\section{Conclusions}

We have found that two-component protons are observed in the midnight plasma sheet under strongly northward IMF $\left(\theta_{\mathrm{IMF}}>45^{\circ}\right)$. The cold proton component with a parallel anisotropy and the isotropic hot component in the midnight region show that the source of the two-component protons is the dusk tail flank. We suggest that prompt transport of the two-component protons from the dusk flank to the midnight region occurs under strongly northward IMF. We propose that the dusk-to-midnight (dawnward) flows result from viscous interaction between the high-latitude portion of the plasma sheet and the lobe cell. Another candidate for plasma supply into the midnight region is vortical structures due to the KH instability that may highly develop around the dusk low-latitude boundary under strongly northward IMF. Prolonged northward IMF intervals result in gradual cooling of the hot proton component in the plasma sheet, and the cooling may be a global phenomenon in the near-Earth magnetotail.

Acknowledgements. We thank T. Nagai for providing the magnetic field data from the MGF instrument on board Geotail spacecraft. We also thank the principal investigators of ACE MAG and SWEPAM experiments and Wind MFI and SWE instruments for providing the solar wind data via CDAWeb. We are grateful to T. Terasawa for providing tools for visualization of Geotail particle data. M. N. Nishino thanks M. Hoshino for fruitful discussion.

Topical Editor I. A. Daglis thanks Y. Ebihara and another anonymous referee for their help in evaluating this paper.

\section{References}

Baumjohann, W.: The near-Earth plasma sheet: An AMPTE/IRM perspective, Space Sci. Rev., 64, 141-163, doi:10.1007/BF00819660, 1993.

Borovsky, J. E., Thomsen, M. F., and Elphic, R. C.: The driving of the plasma sheet by the solar wind, J. Geophys. Res., 103(A8), 17 617-17 639, 1998.

Fairfield, D. H., Otto, A., Mukai, T., Kokubun, S., Lepping, R. P., Steinberg, J. T., Lazarus, A. J., and Yamamoto, T.: Geotail observations of the Kelvin-Helmholtz instability at the equatorial magnetotail boundary for parallel northward fields, J. Geophys. Res., 105(A9), 21 159-21 174, 10.1029/1999JA000316, 2000.

Fujimoto, M., Terasawa, T., Mukai, T., Saito, Y., Yamamoto, T., and Kokubun, S.: Plasma entry from the flanks of the near-Earth magnetotail: Geotail observations, J. Geophys. Res., 103, 43914408, 1998.

Hasegawa H., Fujimoto, M., Maezawa, K., Saito, Y., and Mukai, T.: Geotail observations of the dayside outer boundary region: Interplanetary magnetic field control and dawn-dusk asymmetry, J. Geophys. Res., 108(A4), 1163, doi:10.1029/2002JA009667, 2003.

Hasegawa, H., Fujimoto, M., Takagi, K., Saito, Y., Mukai, T., and Rème, H.: Single-spacecraft detection of rolled-up KelvinHelmholtz vortices at the flank magnetopause, J. Geophys. Res., 111, A09203, doi:10.1029/2006JA011728, 2006.

Hori, T., Maezawa, K., Saito, Y., and Mukai, T.: Average profile of ion flow and convection electric field in the near-Earth plasma sheet, Geophys. Res. Lett., 27, 1623-1626, 2000.

Kokubun, S., Yamamoto, T., Acuña, M. H., Hayashi, K., Shiokawa, K., and Kawano, H.: The GEOTAIL magnetic field experiment, J. Geomag. Geoelectr., 46, 7-21, 1994.

Lavraud, B., Thomsen, M. F., Taylor, M. G. G. T., Wang, Y. L., Phan, T. D., Schwartz, S. J., Elphic, R. C., Fazakerley, A., Rème, H., and Balogh, A.: Characteristics of the magnetosheath electron boundary layer under northward interplanetary magnetic field: Implications for high-latitude reconnection, J. Geophys. Res., 110, A06209, doi:10.1029/2004JA010808, 2005.

Lavraud, B., Thomsen, M. F., Lefebvre, B., Schwartz, S. J., Seki, K., Phan, T. D., Wang, Y. L., Fazakerley, A., Rème, H., and Balogh, A.: Evidence for newly closed magnetosheath field lines at the dayside magnetopause under northward IMF, J. Geophys. Res., 111, A05211, doi:10.1029/2005JA011266, 2006.

Li, W., Raeder, J., Dorelli, J., Øieroset, M., and Phan, T. D.: Plasma sheet formation during long period of northward IMF, Geophys. Res. Lett., 32, L12S08, doi:10.1029/2004GL021524, 2005.

Maezawa, K. and Hori, T.: The distant magnetotail: Its structure, IMF dependence, and thermal properties, New Perspectives on the Earth's Magnetotail, Geophys. Monogr. Vol. 105, edited by: Nishida, A., Baker, D. N., and Cowley, S. W. H., pp. 1-19, American Geophysical Union, Washington, D.C., 1998.

Mukai, T., Machida, S., Saito, Y., Hirahara, H., Terasawa, T., Kaya, N., Obara, T., Ejiri, M., and Nishida, A.: The Low Energy Particle (LEP) experiment onboard the GEOTAIL satellite, J. Geomag. Geoelectr., 46, 669-692, 1994.

Nagai, T., Mukai, T., Yamamoto, T., Nishida, A., Kokubun, S., and Lepping, R. P.: Plasma sheet pressure changes during the substorm growth phase, Geophys. Res. Lett., 24, 963-966, 1997.

Nagai, T., Nakamura, R., Kokubun, S., Saito, Y., Yamamoto, T., Mukai, T., and Nishida, A.: Near-earth plasma sheet behavior 
during substorms, Geophys. Monogr., 104, 213-226, 1998.

Nishino, M. N., Terasawa, T., and Hoshino, M.: Increase of the tail plasma content during the northward interplanetary magnetic field intervals: Case studies, J. Geophys. Res., 107(A9), 1261, doi:10.1029/2002JA009268, 2002.

Nishino, M. N., Fujimoto, M., Terasawa, T., Ueno, G., Maezawa, K., Mukai, T., and Saito, Y.: Geotail observations of temperature anisotropy of the two-component protons in the dusk plasma sheet, Ann. Geophys., 25, 769-777, 2007, http://www.ann-geophys.net/25/769/2007/.

Øieroset, M., Raeder, J., Phan, T. D., Wing, S., McFadden, J. P., Li, W., Fujimoto, M., Rème, H., and Balogh, A.: Global cooling and densification of the plasma sheet during an extended period of purely northward IMF on October 22-24, 2003, Geophys. Res. Lett., L12S07, doi:10.1029/2004GL021523, 2005.

Onsager, T. G., Scudder, J. D., Lockwood, M., and Russell, C. T.: Reconnection at the high-latitude magnetopause during northward interplanetary magnetic field conditions, J. Geophys. Res., 106(A11), 25 467-25 488, 10.1029/2000JA000444, 2001.

Phan, T. D., Paschmann, G., Raj, A., Angelopoulos, V., Larson, D., and Lin, R. P.: Wind observations of the halo/cold plasma sheet, in Astrophysics and Space Science library, Substorms-4, vol. 238, edited by: Kokibun, S. and Kamide, Y., pp. 219-222, Terra Scientific/Kluwer Academic, Boston, 1998.

Roelof, E. D. and Sibeck, D. G.: Magnetopause shape as a bivariate function of interplanetary magnetic field $\mathrm{Bz}$ and solar wind dynamic pressure, J. Geophys. Res., 98, 21 421-21 450, 1993.

Reiff, P. H. and Burch, J. L.: IMF By-dependent plasma flow and Birkeland currents in the dayside magnetosphere: 2. A global model for northward and southward IMF, J. Geophys. Res., 90(A2), 1595-1609, 1985.
Song, P. and Russell, C. T.: Model of the formation of the lowlatitude boundary layer for strongly northward interplanetary magnetic field, J. Geophys. Res., 97(A2), 1411-1420, 1992.

Terasawa, T., Fujimoto, M., Mukai, T., Shinohara, I., Saito, Y., Yamamoto, T., Machida, S., Kokubun, S., Lazarus, A. J., Steinberg, J. T., and Lepping, R. P.: Solar wind control of density and temperature in the near-Earth plasma sheet: Wind/Geotail collaboration, Geophys. Res. Lett., 24, 935-938, 1997.

Traver, D. P., Mitchell, D. G., Williams, D. J., Frank, L. A., and Huang, C. Y.: Two encounters with the flank low-latitude boundary layer: Further evidence for closed field topology and investigation of the internal structure, J. Geophys. Res., 96(A12), $21025-21035,1991$.

Ueno, G, Nakamura, N., Higuchi, T., Tsuchiya, T., Machida, S., Araki, T., Saito, Y., and Mukai, T.: Application of multivariate Maxwellian mixture model to plasma velocity distribution function, J. Geophys. Res., 106(A11), 25 655-25 672, 2001.

Wing, S., Johnson, J. R., Newell, P. T., and Meng, C.-I.: Dawndusk asymmetries, ion spectra, and sources in the northward interplanetary magnetic field plasma sheet, J. Geophys. Res., 110, A08205, doi:10.1029/2005JA011086, 2005.

Wing, S., Johnson, J. R., and Fujimoto, M.: Timescale for the formation of the cold-dense plasma sheet: A case study, Geophys Res. Lett., 33, L23106, doi:10.1029/2006GL027110, 2006.

Zwolakowska, D., Koperski, P., and Popielawska, B.: Plasma populations in the tail during northward IMF, Proceedings of the international conference on substorms (ICS-1), ESA SP-335, 57-62, 1992.

Zwolakowska, D. and Popielawska, B.: Tail plasma domains and the auroral oval: results of mapping based on the Tsyganenko 1989 magnetosphere model, J. Geomag. Geoelectr., 44, 1145$1158,1992$. 